\title{
Distância genética entre linhagens avançadas de germoplasma de algodão com uso de marcadores de RAPD e microssatélites
}

\author{
Ivandilson Pessoa Pinto de Menezes ${ }^{(1)}$, Lúcia Vieira Hoffmann(1), Milena Ferreira Alves(1), \\ Camilo de Lelis Morello(1) e Paulo Augusto Vianna Barroso(1)
}

(1)Embrapa Algodão, Caixa Postal 174, CEP 58107-720 Campina Grande, PB. E-mail: ivppmbio@yahoo.com.br, hoff@cnpa.embrapa.br, milenafalves@yahoo.com.br, morello@cnpa.embrapa.br, pbarroso@cnpa.embrapa.br

Resumo - O objetivo deste trabalho foi selecionar coeficientes de similaridade para serem aplicados a conjuntos de genótipos de algodoeiro com baixa diversidade genética. Analisou-se um conjunto de 65 linhagens e 4 cultivares de algodão, com marcadores de RAPD e SSR, e estimou-se a similaridade genética de acordo com sete coeficientes de similaridade: Coincidência Simples, Rogers \& Tanimoto, Ochiai, Hamman, Jaccard, Dice e Russel \& Rao. A adequação dos coeficientes ao conjunto de genótipos foi verificada por correlação entre as matrizes de distância, índice de consenso entre os dendrogramas e otimização de Tocher. As análises mostraram que o coeficiente de Russel e Rao foi divergente em relação aos demais e seu uso não é recomendável. Entre os parâmetros usados para avaliar a qualidade de informação de cada coeficiente, apenas o índice de consenso estabeleceu diferenças e os classificou em dois grupos: aquele em que a ausência simultânea é considerada e aquele em que ela é desconsiderada. Considerando-se a presença de apenas dois alelos microssatélites por loco e os maiores índices de consenso, os coeficientes de Coincidência Simples, Hamman e Rogers \& Tanimoto devem ser preferidos, quando em conjuntos de genótipos de algodoeiro melhorados e com baixa diversidade.

Termos para indexação: Gossypium hirsutum, diversidade genética, marcadores RAPD, marcadores SSR.

\section{Genetic distance among advanced lineages of cotton germplasm using RAPD and microsatellite markers}

\begin{abstract}
The objective of this work was to select similarity coefficients to be used among sets of cotton genotypes with low genetic diversity. Sixty-five lineages and four cotton cultivars were analyzed by RAPD and SSR markers; and the genetic similarity was estimated by seven similarity coefficients: Simple Matching, Rogers \& Tanimoto, Ochiai, Hamman, Jaccard, Dice and Russel \& Rao. The adequacy of the use of each coefficient to the collected data was verified by correlation between the distance matrices, the consensus index between the dendrograms and the Tocher's optimization method. The coefficient of Russel \& Rao was the most divergent, and its use is not recommended. Among the parameters used to estimate the quality of information provided by each coefficient, differences were observed only by the consensus index, which established two groups: one in which simultaneous absence of bands are taken into account, and other in which it is excluded. Considering the presence of only two microsatellite alleles per polymorphic locus and the higher consensus index coefficients, the Simple Matching, Hamman and Rogers \& Tanimoto coefficients should be preferred when analyzing cotton elite genotypes with low genetic similarity.
\end{abstract}

Index terms: Gossypium hirsutum, genetic diversity, RAPD markers, SSR markers.

\section{Introdução}

A expansão da cotonicultura para o Centro Oeste pode, em grande parte, ser atribuída ao melhoramento genético. Entretanto, a base genética de Gossypium hirsutum que deu origem às cultivares é considerada restrita (Iqbal et al., 2001), e é necessário cuidado, portanto, para que não haja maior estreitamento da base genética das populações, e conseqüentemente redução do ganho de seleção. Estimativas de diversidade podem auxiliar os programas de melhoramento em diversas etapas, particularmente quando da escolha dos genitores para a síntese de populações segregantes. Os principais métodos empregados pelos melhoristas, na obtenção de estimativas de diversidade, baseiam-se na genealogia dos genótipos, em que o coeficiente de parentesco é seu principal representante. Estimativas 
de diversidade baseadas em características qualitativas e quantitativas também são freqüentes, com metodologias univariadas, como a capacidade específica de combinação obtida em delineamentos dialélicos, ou multivariada, como as distâncias genéticas e o estudo de componentes principais (Barroso et al., 2003).

Apesar do número relativamente elevado de publicações sobre diversidade molecular do algodoeiro, não se conhece nenhum programa de melhoramento que use, em sua rotina, tais estimativas para a tomada de decisão. Para que uma medida de diversidade seja empregada pelos melhoristas, é necessário que a estimativa de diversidade tenha sido obtida a partir de um estimador adequado. Assim como em outras culturas, diferentes coeficientes de similaridade e de distância genética foram empregados para estimar a diversidade entre genótipos de algodoeiro, sem que nenhuma razão para a escolha tenha sido explicitada (Lu \& Myers, 2002; Rahman et al., 2002; Rana \& Bhat, 2005). Trabalhos publicados sobre milho (Meyer et al., 2004) e feijoeiro (Emygdio et al., 2003) mostram que os agrupamentos podem variar com a escolha do coeficiente de similaridade, e que a análise da eficiência da projeção gráfica do agrupamento (Cruz, 2001) pode auxiliar na escolha dos coeficientes mais adequados.
O objetivo deste trabalho foi selecionar um coeficiente de similaridade, para se estimar a diversidade genética em um conjunto de genótipos de algodoeiro herbáceo com baixa diversidade.

\section{Material e Métodos}

Foi analisado um conjunto de 69 genótipos de algodoeiro herbáceo, constituído por 4 cultivares e 65 linhagens endogâmicas (Tabela 1), todos desenvolvidos pelo Programa de Melhoramento da Embrapa Algodão, que utilizou o método genealógico. Os genótipos de 1 a 4 e de 5 a 69 são, respectivamente, cultivares e linhagens produzidas pela Embrapa. O código das linhagens inclui o ano em que elas foram selecionadas (número após a sigla CNPA). A maioria dos genótipos provém de cruzamentos com genitores diferentes, que passaram por pelo menos 5 gerações de autofecundação.

O DNA genômico foi extraído de folhas de plantas de 3 a 4 semanas, em que cada genótipo foi representado por um indivíduo. Amostras de tecidos foliares com 50 a $100 \mathrm{mg}$ foram congeladas com nitrogênio líquido e trituradas. Adicionaramse $600 \mu \mathrm{L}$ de tampão de extração $(2 \%$ de CTAB, 1,4 $\mathrm{M}$ de $\mathrm{NaCl}, 0,2 \mathrm{M}$ de EDTA, 0,1 M de Tris $\mathrm{HCl}$ pH 8, 2\% de PVP 40 e $0,2 \%$ de 2 -mercaptoetanol). A suspensão foi incubada a $65^{\circ} \mathrm{C}$ por $30 \mathrm{~min}$,

Tabela 1. Genótipos de algodoeiro empregados na comparação dos coeficientes de similaridade ${ }^{(1)}$.

\begin{tabular}{|c|c|c|c|c|c|}
\hline Número & Genótipo & Número & Genótipo & Número & Genótipo \\
\hline 1 & BRS Aroeira & 24 & CNPA 00999 & 47 & CNPA 013088 \\
\hline 2 & Delta Opal & 25 & CNPA 001021 & 48 & CNPA 011420 \\
\hline 3 & BRS Ipê & 26 & CNPA 001148 & 49 & CNPA 013076 \\
\hline 4 & CNPA ITA90II & 27 & CNPA 001255 & 50 & CNPA 011366 \\
\hline 5 & CNPA 9810004 & 28 & CNPA 001207 & 51 & CNPA 012057 \\
\hline 6 & CNPA 9805948 & 29 & CNPA 00204 & 52 & CNPA 01646 \\
\hline 7 & CNPA 98243 & 30 & CNPA 001088 & 53 & CNPA 011375 \\
\hline 8 & CNPA 9805941 & 31 & CNPA 001093 & 54 & CNPA 011984 \\
\hline 9 & CNPA 9805975 & 32 & CNPA 002099 & 55 & CNPA 011335 \\
\hline 10 & CNPA 98647 & 33 & CNPA 011289 & 56 & CNPA 011097 \\
\hline 11 & CNPA 001212 & 34 & CNPA 011940 & 57 & CNPA 011885 \\
\hline 12 & CNPA 001120 & 35 & CNPA 012091 & 58 & CNPA 0132 \\
\hline 13 & CNPA 00130 & 36 & CNPA 012662 & 59 & CNPA 0113 \\
\hline 14 & CNPA 001072 & 37 & CNPA 013113 & 60 & CNPA 012433 \\
\hline 15 & CNPA 00997 & 38 & CNPA 012887 & 61 & CNPA 0122 \\
\hline 16 & CNPA 001167 & 39 & CNPA 01921 & 62 & CNPA 013033 \\
\hline 17 & CNPA 001156 & 40 & CNPA 012161 & 63 & CNPA 011276 \\
\hline 18 & CNPA 00991 & 41 & CNPA 011340 & 64 & CNPA 012617 \\
\hline 19 & CNPA 001222 & 42 & CNPA 011949 & 65 & CNPA 011272 \\
\hline 20 & CNPA 00174 & 43 & CNPA 0112 & 66 & CNPA 011463 \\
\hline 21 & CNPA 001256 & 44 & CNPA 011149 & 67 & CNPA 013031 \\
\hline 22 & CNPA 00995 & 45 & CNPA 013072 & 68 & CNPA 013109 \\
\hline 23 & CNPA 001077 & 46 & CNPA 01149 & 69 & CNPA 012058 \\
\hline
\end{tabular}

${ }^{(1)}$ Os genótipos de número 1 a 4 e de 5 a 69 são, respectivamente, cultivares e linhagens produzidos pelo Programa de Melhoramento da Embrapa. 
emulsionada com $600 \mu \mathrm{L}$ de clorofórmio e álcool isoamílico (24:1), e as fases foram separadas por centrifugação a $11.700 \mathrm{~g}$ por $10 \mathrm{~min}$. À fase aquosa foi adicionada uma parte de álcool isopropanol gelado (v/v), e a mistura foi centrifugada a $11.700 \mathrm{~g}$ por $10 \mathrm{~min}$. O DNA precipitado foi lavado com álcool a $70 \%$ e absoluto e ressuspenso em tampão TE (10 mM Tris; $1 \mathrm{mM}$ EDTA). Alíquotas do volume total de DNA extraído foram quantificadas por comparação visual das bandas, geradas de uma série de concentrações conhecidas de DNA fago $\lambda$ $(50,100,200$ e $300 \mathrm{ng})$ em géis de agarose a $0.8 \%$. Posteriormente, o DNA foi diluído em TE (pH 8) a $10 \mathrm{ng} \mu \mathrm{L}^{-1}$ para as reações de PCR.

Obtiveram-se marcadores RAPD por meio de 38 iniciadores de $10 \mathrm{~b}$ dos conjuntos Operon A (10, $13,18), \mathrm{C}(12), \mathrm{E}(16,19,20), \mathrm{M}(4,5,7,8,9,11), \mathrm{N}$ $(2,3,4,5,6,7,9,11,12,14,15,17), \mathrm{P}(1,2,3,6,9,17)$ e Z $(7,11,12,16,17,19,20)$. As reações PCR foram feitas com desnaturação inicial a $94^{\circ} \mathrm{C}$ por $5 \mathrm{~min}$, seguida de 45 ciclos compostos por: desnaturação a $94^{\circ} \mathrm{C}$ por $1 \mathrm{~min}$, anelamento do iniciador a $35^{\circ} \mathrm{C}$ por $1 \mathrm{~min}$ e amplificação a $72^{\circ} \mathrm{C}$ por $2 \mathrm{~min}$. Ao final dos 45 ciclos, uma amplificação adicional a $72^{\circ} \mathrm{C}$ por $5 \mathrm{~min}$ foi realizada. Os fragmentos obtidos foram analisados em géis de agarose, corados com brometo de etídeo, e observados em transluminador de ultravioleta.

Marcadores microssatélites foram obtidos com uso dos 19 pares iniciadores: BNL1665, BNL3995, BNL3558, BNL3008, BNL1597, BNL1059, BNL3816, BNL3792, BNL2496, BNL3902, BNL1434, BNL2590, BNL3408, BNL2255, BNL3084, BNL2572, BNL3147, BNL3646 e CM43 (Liu et al., 2000). As reações de amplificação foram realizadas com o programa tipo "touch down" conforme Liu et al. (2000), com as seguintes etapas: desnaturação inicial a $95^{\circ} \mathrm{C}$ por $2 \mathrm{~min} ; 10$ ciclos de $94^{\circ} \mathrm{C}$ por $15 \mathrm{~s}, 65^{\circ} \mathrm{C}$ por $30 \mathrm{~s}-$ com redução de um grau a cada ciclo, e uma extensão a $72^{\circ} \mathrm{C}$ por $1 \mathrm{~min}$; 35 ciclos de $94^{\circ} \mathrm{C}$ por $15 \mathrm{~s}, 55^{\circ} \mathrm{C}$ por $30 \mathrm{~s} \mathrm{e} 72^{\circ} \mathrm{C}$ por $1 \mathrm{~min}$; extensão final a $72^{\circ} \mathrm{C}$ por $6 \mathrm{~min}$. Os fragmentos amplificados foram separados em eletroforese vertical, em gel desnaturante de poliacrilamida $6 \%$, e visualizados após coloração com prata, conforme descrito por Creste et al. (2001).

Os marcadores RAPD foram avaliados, tendo-se atribuído os valores 1 para presença e 0 para ausência da banda de marcadores. Os marcadores microssatélites também foram avaliados como marcadores dominantes, tendo sido atribuídos os valores 1 para o alelo maior e 0 para o alelo menor. A matriz binária foi empregada para se estimar a similaridade genética entre cada par de genótipos, tendo sido empregados sete coeficientes de similaridade: Coincidência Simples, Rogers \& Tanimoto, Ochiai, Hamman, Jaccard, Dice (Nei \& Li) e Russel \& Rao. As análises de agrupamento dos genótipos para cada coeficiente foram obtidas a partir do método de média aritmética não ponderada ("unweighted pair group method with arithmetic mean"- UPGMA) pelo programa NTSYS ("Numerical Taxonomy and Multivariate System") versão 2.0 (Rohlf, 1992). Utilizou-se o método de otimização de Tocher, para a determinação de grupos de linhagens com o mesmo padrão de similaridade, pelo programa Genes (Cruz, 2001).

A comparação entre as matrizes de similaridade, estimada para cada coeficiente de similaridade, foi feita com o módulo MAXCOMP do programa NTSYS-pc. A normalização da estatística $Z$ de Mantel foi usada para se determinar a associação entre duas matrizes. A diferença entre os dendrogramas foi estimada com o índice de consenso (Cic), que produz uma estimativa relativa de similaridade entre os dendrogramas, calculado pelo programa NTSYS (Rohlf, 1992).

A projeção da matriz de similaridade em espaço bidimensional (Cruz \& Vianna, 1994) foi realizada com o programa Genes (Cruz, 2001). A comparação entre os diferentes coeficientes de similaridade foi realizada por meio da correlação entre as distâncias originais e as distâncias obtidas pela dispersão bidimensional, pelo grau de distorção e pelo valor de estresse. A qualidade do ajuste entre a distância genética original e a obtida na projeção gráfica do dendrograma é estimada pelo parâmetro estresse, considerado insatisfatório, regular, bom, excelente e perfeito, quando os valores de estresse são 40, 20, 10, 5 e $0 \%$, respectivamente (Kruskal, 1964; Meyer et al., 2004).

\section{Resultados e Discussão}

Os 38 iniciadores RAPD amplificaram 280 fragmentos de DNA, dos quais 70 foram polimórficos $(25 \%)$. Os fragmentos polimórficos foram amplificados por 28 iniciadores, com média de 2,5 e amplitude de 1 a 8 fragmentos polimórficos por iniciador. 
Dos pares de iniciadores SSR, entre os 19 testados, 9 foram polimórficos: BNL3008, 3816, 2496, 3902, 1434, 2590, 3408, 3255 e CM43. O polimorfismo encontrado foi de $47 \%$. A maior taxa de polimorfismo em SSR deve ter ocorrido por terem sido utilizados iniciadores já sabidamente polimórficos em outros acessos de algodão (Liu et al., 2000; Bertini et al., 2006). Cada iniciador amplificou apenas um loco, e o número de alelos produzidos nos locos polimórficos foi igual a 2, com tamanhos idênticos aos previamente descritos (Liu et al., 2000; Gutiérrez et al., 2002; Bertini et al., 2006). Todas as linhagens e cultivares foram sempre homozigotas, fato coerente com o nível elevado de endogamia esperado nos genótipos. Assim, as informações fornecidos pelos marcadores SSR e RAPD foram similares.

As matrizes de similaridade calculadas a partir dos sete diferentes coeficientes estudados apresentaram alto valor de correlação de Pearson e de Spearman, o que indica elevada concordância entre as estimativas obtidas pelos diferentes coeficientes (Tabela 2). A correlação verificada entre os coeficientes de Coincidência Simples, Hamman e Rogers \& Tanimoto mostrou não haver diferença na utilização desses coeficientes. Os coeficientes foram próximos de 1, com exceção dos relativos aos de Russel \& Rao, o mais discrepante. Ainda, exceto o coeficiente de Russel \& Rao, todos os demais coeficientes de similaridade foram máximos entre as cultivares BRS Ipê e CNPA Ita 90II, cuja elevada similaridade deveu-se à BRS Ipê ter sido obtida por meio de seleção dentro de CNPA Ita 90. Os menores coeficientes de similaridade foram observados entre a linhagem CNPA GO 2001646 e as linhagens CNPA GO 20001167 e CNPA GO 2000 1093. Embora haja exceções, a maioria dos genótipos avaliados

Tabela 2. Coeficientes de correlação de Spearman, acima da diagonal, e de Pearson, abaixo da diagonal, entre as estimativas de similaridade genética entre cultivares e linhagens de algodão herbáceo ${ }^{(1)}$.

\begin{tabular}{lccccccc}
\hline & CS & RT & H & O & J & D & RR \\
\hline CS & & 1,00 & 1,00 & 0,98 & 0,98 & 0,98 & 0,70 \\
RT & 1,00 & & 1,00 & 0,98 & 0,98 & 0,98 & 0,70 \\
H & 1,00 & 1,00 & & 0,98 & 0,98 & 0,98 & 0,70 \\
O & 0,98 & 0,97 & 0,98 & & 1,00 & 1,00 & 0,83 \\
J & 0,98 & 0,98 & 0,98 & 1,00 & & 1,00 & 0,83 \\
SD & 0,98 & 0,97 & 0,98 & 1,00 & 1,00 & & 0,83 \\
RR & 0,75 & 0,74 & 0,75 & 0,86 & 0,86 & 0,86 & \\
\hline
\end{tabular}

${ }^{(1)}$ CS, Coincidência Simples; RT, Rogers \& Tanimoto; O, Ochiai; J, Jaccard; D, Dice; H, Hamman; RR, Russel \& Rao. apresentou similaridade elevada, o que concorda com análises anteriores, realizadas em conjuntos semelhantes de genótipos de algodoeiro (Iqbal et al., 2001; Gutiérrez et al., 2002; Lu \& Myers, 2002; Rahman et al., 2002; Zhang et al., 2005; Bertini et al., 2006). Segundo McCarty et al. (2007), os programas de melhoramento do algodoeiro estão baseados no uso de limitada diversidade genética e as cultivares e linhagens elite possuem base genética estreita. A alta uniformidade genética deve-se ao elevado número de seleções dentro das cultivares e ao uso continuado de um pequeno conjunto de genitores (Bowman, 2000), o que pode aumentar a vulnerabilidade da cultura e estabelecer patamares de produtividade (Van Esbraeck \& Bowman, 1998; Carvalho et al., 2003).

Os índices de consenso (Cic) entre os dendrogramas obtidos a partir dos diferentes coeficientes de similaridade variaram de 0,17 a 1,00 (Tabela 3). O índice de consenso comparou a proporção de agrupamentos comuns entre os dendrogramas, e os valores estimados separaram os coeficientes em três grupos: Russel \& Rao; Coincidência Simples, Rogers \& Tanimoto e Hamman; Jaccard, Dice e Ochiai. O coeficiente de Russel \& Rao produziu valores de coincidência muito baixos, com índices de consenso entre 0,17 e 0,20 , e é, portanto, o coeficiente com maior disparidade em relação aos demais. O segundo grupo apresentou índices de consenso iguais ou próximos a um, o que indica que praticamente todos os agrupamentos presentes no dendrograma foram idênticos. No terceiro grupo, o consenso entre os dendrogramas de Jaccard e Dice foi elevado, porém os valores verificados com Ochiai foram menores. Quando coeficientes pertencentes aos dois grupos

Tabela 3. Comparação da similaridade dos dendrogramas obtidos por sete diferentes coeficientes de similaridade e agrupados com método UPGMA, por meio do índice de consenso $\mathrm{CIc}^{(1)}$.

\begin{tabular}{lcccccc}
\hline & CS & RT & H & O & J & SD \\
\hline RT & 0,97 & 1,00 & & & & \\
H & 1,00 & 0,97 & 1,00 & & & \\
O & 0,55 & 0,55 & 0,55 & 1,00 & & \\
J & 0,64 & 0,64 & 0,64 & 0,82 & 1,00 & \\
SD & 0,61 & 0,61 & 0,61 & 0,80 & 0,94 & 1,00 \\
RR & 0,19 & 0,20 & 0,19 & 0,17 & 0,20 & 0,20 \\
\hline
\end{tabular}

${ }^{(1)}$ CS, Coincidência Simples; RT, Rogers \& Tanimoto; O, Ochiai; J, Jaccard; D, Dice; H, Hamman; RR, Russel \& Rao. 
diferentes foram comparados, os valores de consenso foram intermediários (entre 0,55 e 0,61 ), o que indica existência de diferenças elevadas entre os agrupamentos.

Apesar dos índices de consenso relativamente baixos entre os dendrogramas dos coeficientes que consideraram ou não a ausência simultânea, a estrutura dos agrupamentos foi similar, exceto, novamente, aquele gerado por Russel \& Rao.
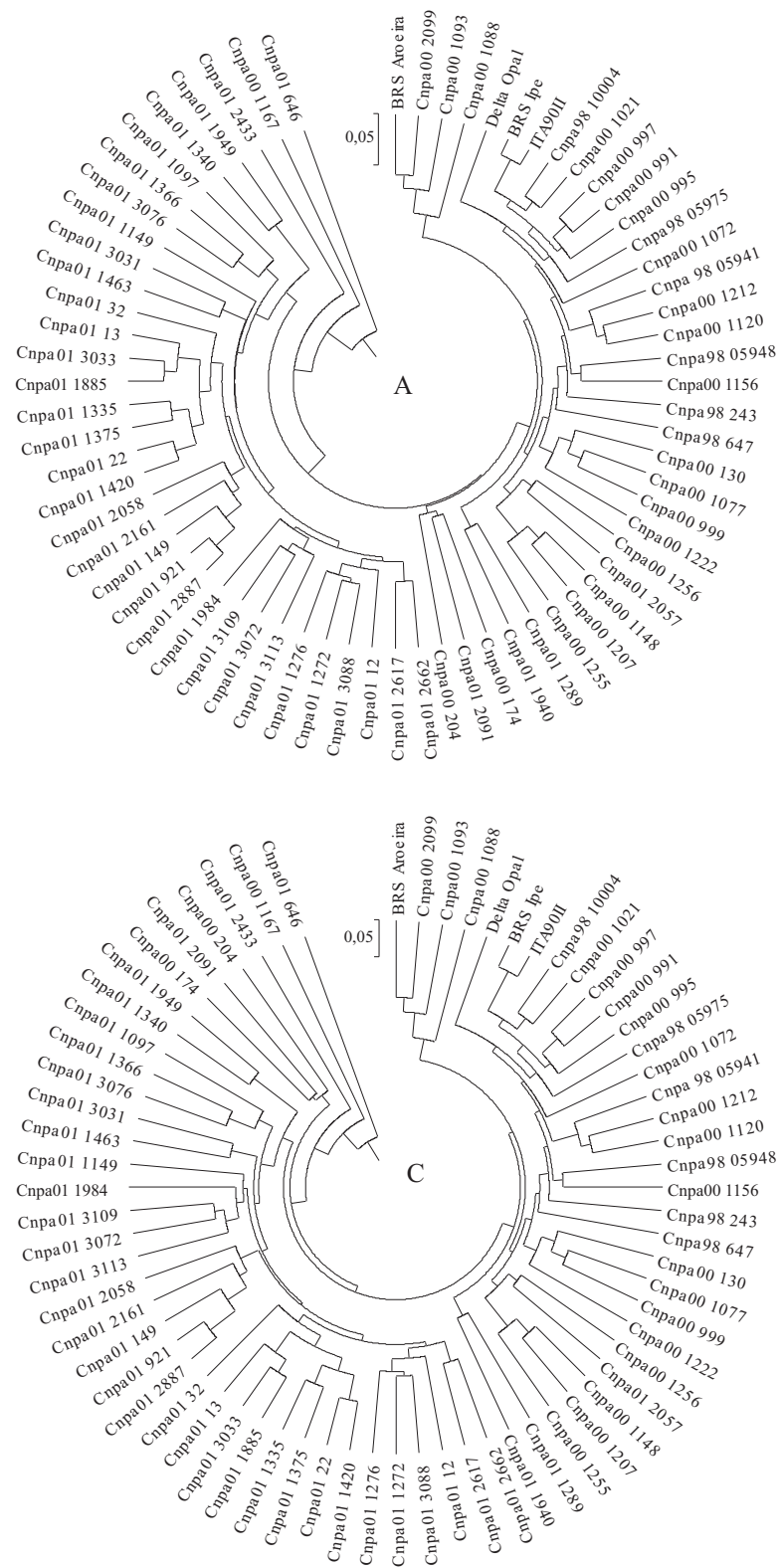

As diferenças entre os dendrogramas devem-se a alterações dentro da estrutura dos agrupamentos principais (Figuras 1 e 2). Todos os dendrogramas tiveram dois agrupamentos principais e três linhagens que não se agruparam. $O$ primeiro grupo foi formado quase exclusivamente por linhagens selecionadas em 2001 (CNPA 01), e o segundo englobou as cultivares, a totalidade das linhagens de 1998, algumas linhagens de 2001 e a maioria das linhagens
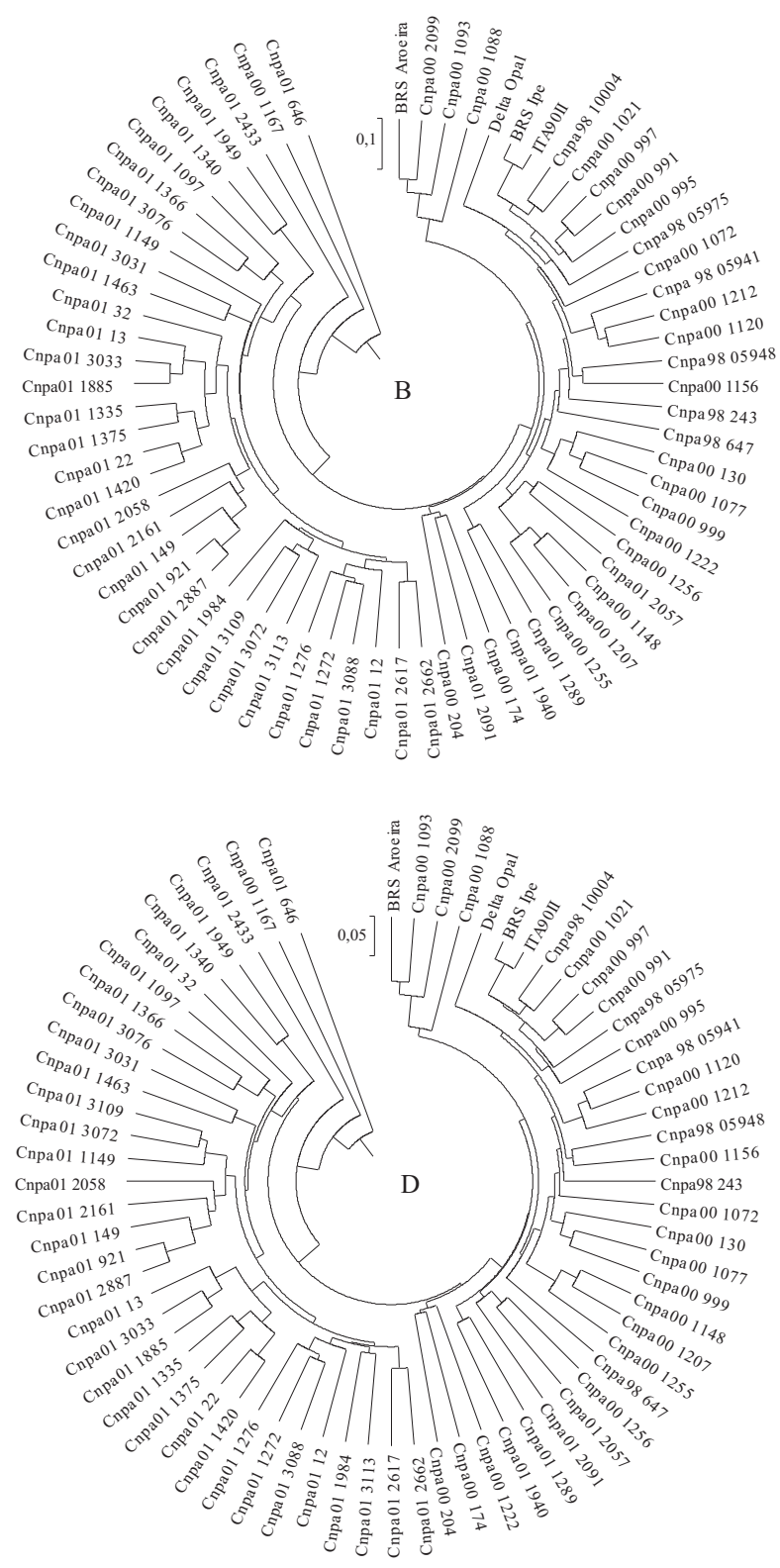

Figura 1. Dendrogramas obtidos pelo agrupamento, segundo UPGMA, dos 69 genótipos. A, Coincidência Simples; B, Hamman; C, Rogers \& Tanimoto; D, Jaccard. 
de 2000. Todos esses dendrogramas foram capazes de verificar que o conjunto de linhagens selecionadas em 2001 era diferente das cultivares e das linhagens selecionadas em anos anteriores. Porém, a relação entre os genótipos dentro de cada um dos grandes grupos foi muito similar entre os dendrogramas baseados nos coeficientes de Coincidência Simples, Hamman e Roger e Tanimoto, bem como entre os coeficientes de Dice \& Jaccard. Da mesma maneira que observado por Duarte et al. (1999), as diferenças nos agrupamentos foram verificadas entre genótipos com similaridades mais baixas.

O nível de estresse entre todas as projeções gráficas dos respectivos coeficientes utilizados foi acima de $65 \%$ (Tabela 4). Assim, todos os coeficientes estudados na análise comparativa, quanto à eficiência de projeção das matrizes de dissimilaridade entre as cultivares e linhagens de algodão, em espaço bidimensional, foram insatisfatórios conforme a classificação de adaptabilidade de projeção gráfica
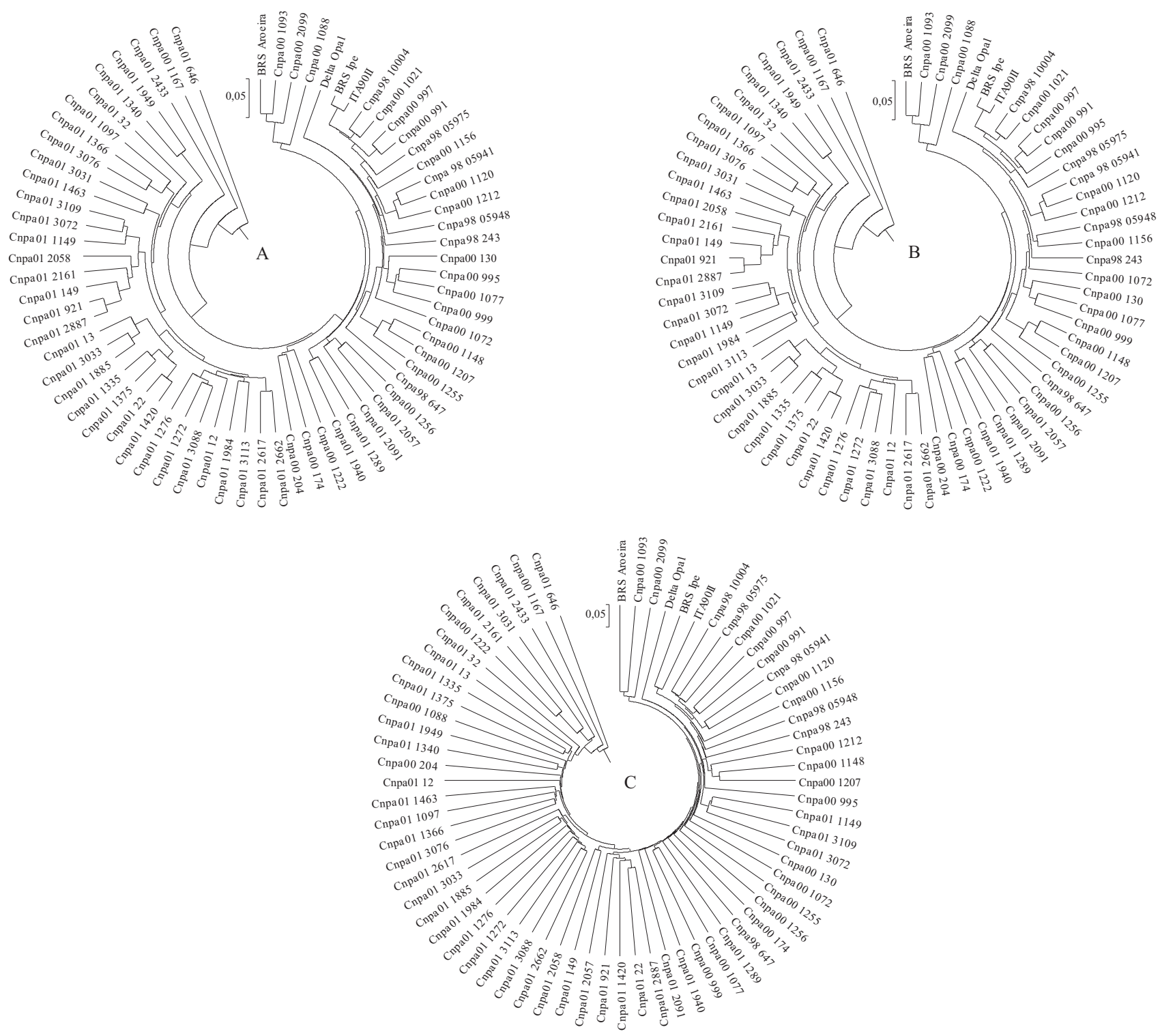

Figura 2. Dendrogramas obtidos pelo agrupamento, segundo UPGMA, dos 69 genótipos. A, Dice; B, Ochiai; C, Russel \& Rao. 
de Kruskal (1964). O elevado nível de estresse obtido impede que comparações sejam realizadas entre os coeficientes de similaridade. Portanto, o uso de projeções bidimensionais, em conjuntos

Tabela 4. Parâmetros utilizados na análise da eficiência da projeção gráfica das distâncias genéticas em espaço bidimensional e correlações cofenéticas.

\begin{tabular}{lccc}
\hline Coeficiente & \multicolumn{3}{c}{ Análise de eficiência } \\
\cline { 2 - 4 } & Distorção (\%) & Correlação & Estresse (\%) \\
\hline Coincidência Simples & 35,212 & 0,081 & 68,698 \\
Rogers \& Tanimoto & 30,653 & 0,106 & 67,209 \\
Hamman & 34,416 & 0,123 & 66,963 \\
Ochiai & 39,510 & 0,104 & 65,117 \\
Jaccard & 27,969 & 0,080 & 66,399 \\
Sorencen Dicer & 14,246 & 0,053 & 88,385 \\
Russel \& Rao & 48,745 & 0,023 & 65,411 \\
\hline
\end{tabular}

de genótipos de algodoeiro similares aos usados no presente trabalho, deve ser feito com cautela, conforme já havia sido verificado em milho por Meyer et al. (2004).

A aplicação do método de otimização de Tocher ao agrupamento dos genótipos resultou na formação de 35 grupos idênticos, para seis coeficientes de similaridade, e de apenas dois grupos para o coeficiente de Russel \& Rao (Tabela 5). Novamente a informação fornecida pelo coeficiente de Russel \& Rao foi discrepante dos demais. A igualdade entre os agrupamentos gerados pelo método de Tocher ratifica a similaridade no conteúdo de informação fornecida pelos coeficientes que consideram e que não consideram a ausência simultânea para as estimativas de similaridade.

Tabela 5. Agrupamento de cultivares e linhagens de algodão, pelo método de otimização de Tocher, considerando-se coeficientes de similaridade de Coincidência Simples (CS), Rogers \& Tanimoto (RT), Ochiai (O), Jaccard (J), Dice (D), Hamman (H) e Russel \& Rao (RR).

\begin{tabular}{|c|c|c|c|c|c|c|c|}
\hline \multirow[t]{2}{*}{ Grupo } & \multicolumn{7}{|c|}{ Coeficientes de similaridade } \\
\hline & $\mathrm{CS}$ & $\mathrm{H}$ & RT & $\mathrm{O}$ & $\mathrm{J}$ & $\mathrm{D}$ & RR \\
\hline 1 & 1,2 & 1,2 & 1,2 & 1,2 & 1,2 & 1,2 & $\begin{array}{l}1,3,5,7,9,11,13,15,17,19,21,23,25,27,29,31,33,35, \\
37,39,41,43,45,47,49,51,53,55,57,59,61,63,65,67,69\end{array}$ \\
\hline 2 & 3,5 & 3,5 & 3,5 & 3,5 & 3,5 & 3,5 & $\begin{array}{l}2,4,6,8,10,12,14,16,18,20,22,24,26,28,30,32,34,36 \\
38,40,42,44,46,48,50,52,54,56,58,60,62,64,66,68\end{array}$ \\
\hline 3 & 4,6 & 4,6 & 4,6 & 4,6 & 4,6 & 4,6 & \\
\hline 4 & 7,9 & 7,9 & 7,9 & 7,9 & 7,9 & 7,9 & \\
\hline 5 & 8,10 & 8,10 & 8,10 & 8,10 & 8,10 & 8,10 & \\
\hline 6 & 11,13 & 11,13 & 11,13 & 11,13 & 11,13 & 11,13 & \\
\hline 7 & 12,14 & 12,14 & 12,14 & 12,14 & 12,14 & 12,14 & \\
\hline 8 & 15,17 & 15,17 & 15,17 & 15,17 & 15,17 & 15,17 & \\
\hline 9 & 16,18 & 16,18 & 16,18 & 16,18 & 16,18 & 16,18 & \\
\hline 10 & 19,21 & 19,21 & 19,21 & 19,21 & 19,21 & 19,21 & \\
\hline 11 & 20,22 & 20,22 & 20,22 & 20,22 & 20,22 & 20,22 & \\
\hline 12 & 23,25 & 23,25 & 23,25 & 23,25 & 23,25 & 23,25 & \\
\hline 13 & 24,26 & 24,26 & 24,26 & 24,26 & 24,26 & 24,26 & \\
\hline 14 & 27,29 & 27,29 & 27,29 & 27,29 & 27,29 & 27,29 & \\
\hline 15 & 28,30 & 28,30 & 28,30 & 28,30 & 28,30 & 28,30 & \\
\hline 16 & 31,33 & 31,33 & 31,33 & 31,33 & 31,33 & 31,33 & \\
\hline 17 & 32,34 & 32,34 & 32,34 & 32,34 & 32,34 & 32,34 & \\
\hline 18 & 35,37 & 35,37 & 35,37 & 35,37 & 35,37 & 35,37 & \\
\hline 19 & 36,38 & 36,38 & 36,38 & 36,38 & 36,38 & 36,38 & \\
\hline 20 & 39,41 & 39,41 & 39,41 & 39,41 & 39,41 & 39,41 & \\
\hline 21 & 40,42 & 40,42 & 40,42 & 40,42 & 40,42 & 40,42 & \\
\hline 22 & 43,45 & 43,45 & 43,45 & 43,45 & 43,45 & 43,45 & \\
\hline 23 & 44,46 & 44,46 & 44,46 & 44,46 & 44,46 & 44,46 & \\
\hline 24 & 47,49 & 47,49 & 47,49 & 47,49 & 47,49 & 47,49 & \\
\hline 25 & 48,50 & 48,50 & 48,50 & 48,50 & 48,50 & 48,50 & \\
\hline 26 & 51,53 & 51,53 & 51,53 & 51,53 & 51,53 & 51,53 & \\
\hline 27 & 52,54 & 52,54 & 52,54 & 52,54 & 52,54 & 52,54 & \\
\hline 28 & 55,57 & 55,57 & 55,57 & 55,57 & 55,57 & 55,57 & \\
\hline 29 & 56,58 & 56,58 & 56,58 & 56,58 & 56,58 & 56,58 & \\
\hline 30 & 59,61 & 59,61 & 59,61 & 59,61 & 59,61 & 59,61 & \\
\hline 31 & 60,62 & 60,62 & 60,62 & 60,62 & 60,62 & 60,62 & \\
\hline 32 & 63,65 & 63,65 & 63,65 & 63,65 & 63,65 & 63,65 & \\
\hline 33 & 64,66 & 64,66 & 64,66 & 64,66 & 64,66 & 64,66 & \\
\hline 34 & 67,69 & 67,69 & 67,69 & 67,69 & 67,69 & 67,69 & \\
\hline 35 & 68 & 68 & 68 & 68 & 68 & 68 & \\
\hline
\end{tabular}


De acordo com as análises realizadas, o coeficiente de Russel \& Rao foi o mais discrepante, resultado já verificado em relação a outras espécies (Duarte et al., 1999; Emygdio et al., 2003; Meyer et al., 2004; Balestre et al., 2008). Seu uso em populações de algodoeiro similares às empregadas no presente trabalho, com baixa variabilidade e homozigóticas, não parece ser recomendável. Os demais coeficientes forneceram informações similares e foram capazes de classificar da mesma maneira os genótipos mais divergentes. Os coeficientes de correlação entre as matrizes de distância e o índice de consenso entre os dendrogramas foram capazes de discriminar os coeficientes em dois grupos. Um grupo foi composto pelos coeficientes de Roger \& Tanimoto, Coincidência Simples e Hamman, e o outro por Jaccard, Ochiai e Dice. Considerando-se os valores dos índices de consenso, os coeficientes do primeiro grupo seriam mais adequados a este conjunto de dados. Esta conclusão é reforçada pelo tipo de polimorfismo nos locos microssatélites (amplo predomínio de dois alelos por loco) e a presença exclusiva de indivíduos homozigotos, verificada no presente estudo e em outros trabalhos realizados com genótipos similares de algodoeiro (Gutiérrez et al., 2002; Bertini et al., 2006; Lacape et al., 2007). Todos os coeficientes desse grupo apresentaram bom desempenho e podem ser usados em conjuntos de genótipos de algodoeiro com elevada similaridade, o que fornece informações idênticas ou quase idênticas. Ressalva-se que esses coeficientes devem ser usados apenas em conjuntos de genótipos com baixa diversidade. Em conjuntos com maior variabilidade, devem-se preferir os coeficientes que desconsideram ausências simultâneas, como Jaccard e Dice.

\section{Conclusões}

1. O coeficiente de Russel \& Rao não deve ser usado para estabelecer relações filogenéticas entre genótipos de algodoeiro com baixa diversidade.

2. Os coeficientes Coincidência Simples, Rogers \& Tanimoto e Hamman são adequados para a realização de estudos filogenéticos, em conjuntos de genótipos de algodoeiro com baixa diversidade.

3. Todos os coeficientes analisados são inadequados para a projeção das médias da distância genética calculada entre aos pares das cultivares e linhagens de algodão, em espaço bidimensional.

\section{Referências}

BALESTRE, M.; VON PINHO, R.G.; SOUZA, J.C.; LIMA, J.L. Comparison of maize similarity and dissimilarity genetic coefficients based on microsatellite markers. Genetics and Molecular Research, v.7, p.695-705, 2008.

BARROSO, P.A.V.; GERALDI, I.O.; VIEIRA, M.L.C.; PULCINELLI, C.E.; VENCOVSKY, R.; DIAS, C.T. dos S. Predicting performance of soybean populations using genetic distances estimated with RAPD markers. Genetics and Molecular Biology, v.26, p.343-348, 2003.

BERTINI, C.H.C. de M.; SCHUSTER, I.; SEDIYAMA, T.; BARROS, E.G. de; MOREIRA, M.A. Characterization and genetic diversity analysis of cotton cultivars using microsatellites. Genetics and Molecular Biology, v.29, p.321-329, 2006.

BOWMAN, D.T. Attributes of public and private cotton breeding programs. Journal of Cotton Science, v.4, p.130-136, 2000.

CARVALHO, L.P. de; LANZA, M.A.; FALLIERI, J.; SANTOS, J.W. dos. Análise da diversidade genética entre acessos de banco ativo de germoplasma de algodão. Pesquisa Agropecuária Brasileira, v.38, p.1149-1155, 2003.

CRESTE, S.; TULMANN NETO, A.; FIGUEIRA, A. Detection of single sequence repeat polymorphisms in denaturing polyacrylamide sequencing gels by silver staining. Plant Molecular Biology Reporter, v.19, p.299-306, 2001.

CRUZ, C.D. Programa Genes: versão Windows, aplicativo computacional em genética e estatística. Viçosa: UFV, 2001. $648 \mathrm{p}$.

CRUZ, C.D.; VIANA, J.M.S. A methodology of genetic divergence analysis based on sample uni projection on two-dimensional space. Revista Brasileira de Genética, v.17, p.69-73, 1994.

DUARTE, J.M.; SANTOS, J.B. dos; MELO, L.C. Comparison of similarity coefficients based on RAPD markers in the common bean. Genetics and Molecular Biology, v.22, p.427-432, 1999.

EMYGDIO, B.M.; ANTUNES, I.F.; CHOER, E.; JORGE, J.L. Eficiência de coeficientes de similaridade em genótipos de feijão mediante marcadores RAPD. Pesquisa Agropecuária Brasileira, v.38, p.243-250, 2003.

GUTIÉRREZ, O.A.; BASU, S.; SAHA, S.; JENKINS, J.N.; SHOEMARKER, D.B.; CHEATHAM, C.L.; MCCARTY JUNIOR, J.C. Genetic distance among selected cotton genotypes and its relationship with $F_{2}$ performance. Crop Science, v.42, p.1841-1847, 2002.

IQBAL, M.J.; REDDY, O.U.K.; EL-ZIK, K.M.; PEPPER, A.E. Agenetic bottleneck in the 'evolution under domestication' of upland cotton Gossypium hirsutum L. examined using DNA fingerprinting. Theoretical and Applied Genetics, v.103, p.547-554, 2001.

KRUSKAL, J.B. Multidimensional scaling by optimizing goodness of fit to a nonmetric hypothesis. Psychometrika, v.29, p.1-27, 1964. 
LACAPE, J.M.; DESSAUW, D.; RAJAB, M.; NOYER, J.L.; HAU, B. Microsatellite diversity in tetraploid Gossypium germplasm: assembling a highly informative genotyping set of cotton SSRs. Molecular Breeding, v.19, p.45-58, 2007.

LIU, S.; SAHA, S.; STELLY, D.; BURR, B.; CANTRELL, R.G. Chromosomal assignment of microsatellite loci in cotton. Journal of Heredity, v.91, p.326-332, 2000.

LU, H.J.; MYERS, G.O. Genetic relationships and discrimination of ten influential upland cotton varieties using RAPD markers. Theorical and Applied Genetics, v.105, p.325-331, 2002.

MCCARTY, J.C.; WU, J.; JENKINS, J.N. Use of primitive derived cotton accessions for agronomic and fiber traits improvement. Crop Science, v.47, p.100-110, 2007.

MEYER, A.D.; GARCIA, A.A.F.; SOUZA, A.P.; SOUZA, C.L. Comparation of similarity used for cluster analysis with dominant markers in maize (Zea mays L.). Genetics and Molecular Biology, v.27, p.83-91, 2004.
RAHMAN, M.; HUSSAIN, D.; ZAFAR, Y. Estimation of genetic divergence among elite cotton cultivars: genotypes by DNA fingerprinting technology. Crop Science, v.42, p.2137-2144, 2002.

RANA, M.K.; BHAT, K.V. RAPD markers for genetic diversity study among Indian cotton cultivars. Current Science, v.88, p.1956-1961, 2005.

ROHLF, F.J. NTSYS-pc numerical taxonomy and multivariate analysis system: version 1.7. New York: Exeter Software, 1992. 236p.

VAN ESBROECK, G.; BOWMAN, D.T. Cotton germplasm diversity and its importance to cultivar development. Journal of Cotton Science, v.2, p.121-129, 1998.

ZHANG, J.; LU, Y.; CANTRELL, G.R.; HUGHS, E. Molecular marker diversity and field performance in commercial cotton cultivars evaluated in the Southwestern USA. Crop Science, v.45, p.1483-1489, 2005.

Recebido em 25 de março de 2008 e aprovado em 25 de setembro de 2008 